\title{
EFEITO DE 6-BENZILAMINOPURINA E ÁCIDO NAFTALENOACÉTICO SOBRE A PROPAGAÇÃO in vitro DE Hancornia speciosa Gomes
}

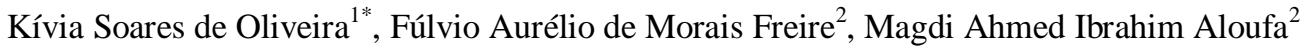 \\ ${ }^{1}$ Universidade Federal do Rio Grande do Norte, Programa de Pós-Graduação em Desenvolvimento e Meio Ambiente, Natal, Rio Grande do \\ Norte, Brasil - kiviaoliv@yahoo.com.br* \\ ${ }^{2}$ Universidade Federal do Rio Grande do Norte, Departamento de Botânica, Ecologia e Zoologia, Natal, Rio Grande do Norte, Brasil - \\ fulvio@cb.ufrn.br; magdialoufal@gmail.com
}

Recebido para a publicação: 18/11/2015 - Aceito para a publicação: 04/07/2016

\begin{abstract}
Resumo
A mangabeira (Hancornia speciosa Gomes) é uma espécie arbórea nativa do Nordeste de grande importância socioeconômica, ambiental e medicinal. Na última década, a intensificação da ação antrópica vem contribuindo para a redução significativa de suas áreas remanescentes e, consequentemente, de sua diversidade genética, o que justifica a realização de estudos relacionados à propagação da espécie. O objetivo deste trabalho foi testar o efeito de diferentes concentrações de 6-benzilaminopurina (BAP) e ácido naftalenoacético (ANA) sobre a indução de brotações em explantes nodais de mangabeira. Estes foram obtidos de plântulas germinadas in vitro e inoculados em meio MS básico e MS suplementado com 1,5; 2,5 e 3,5 mg. $\mathrm{L}^{-1}$ de BAP e 0,1 e $0,5 \mathrm{mg} . \mathrm{L}^{-1}$ de ANA, sendo mantidos em sala de crescimento durante 30 dias sob condições controladas de temperatura, fotoperíodo e luminosidade. O delineamento experimental utilizado foi o inteiramente casualizado, com doze tratamentos e três repetições, sendo cada repetição composta por 10 unidades experimentais. As variáveis observadas foram: formação de brotos, número de brotos por explante, presença de calos, contaminação e sobrevivência. Os dados foram avaliados estatisticamente através da análise de modelo linear generalizado. Os resultados indicaram diferença significativa entre os tratamentos e os reguladores de crescimento vegetal, para todas as variáveis. Dessa forma, na ausência de BAP e ANA, os explantes apresentam-se mais responsivos em relação à taxa de multiplicação e ao número de brotações, sendo, portanto, desnecessário o uso desses reguladores de crescimento para a propagação in vitro de mangabeira.
\end{abstract}

Palavras-chave: Mangabeira; micropropagação; citocinina; auxina.

\begin{abstract}
Effect of 6-benzylaminopurine and naflalenoacético acid on in vitro propagation of Hancornia speciosa Gomes. The mangabeira (Hancornia speciosa Gomes) is a native tree species of the Northeast of Brazil, of great importance socio-economic, environmental and medicinal. In the last decade, the intensification of human action has contributed to the significant reduction in its remaining areas, and hence their genetic diversity, which justify the need for studies related to the propagation of the species. The objective of this study was to test the effect of different concentrations of 6-benzylaminopurine (BAP) and naphthalene acetic acid (NAA) on the shoot induction in nodal explants mangabeira. These were obtained from seedlings germinated in vitro and inoculated in MS medium and MS supplemented with: $1.5 ; 2.5$ and $3.5 \mathrm{mg} . \mathrm{L}^{-1}$ BAP and 0.1 to $0.5 \mathrm{mg} . \mathrm{L}^{-1} \mathrm{NAA}$ and kept in growth room for 30 days under controlled conditions of temperature, photoperiod and luminosity. The experimental design was randomized with 12 treatments, 3 replications and each replication consisting of 10 experimental units. The variables were: formation of buds, number of shoots per explant, callus presence, contamination and survival. The data were statistically analyzed by generalized linear model analysis. There were significant differences between treatments with plant growth regulators, for all variables. Therefore, in the absence of BAP and NAA explants have to be more responsive in relation to the rate of multiplication and the number of shoots is therefore unnecessary to use these growth regulators in vitro propagation of mangabeira.

Keywords: Mangabeira; micropropagation; cytokinin; auxin.
\end{abstract}

\section{INTRODUÇÃO}

Entre as espécies nativas do Brasil que se destacam pela sua potencialidade, encontra-se a mangabeira (Hancornia speciosa Gomes). Essa frutífera tropical, pertencente à família Apocynaceae, apresenta ampla distribuição geográfica, que vai desde os Tabuleiros Costeiros e Baixadas Litorâneas do Nordeste até as regiões Centro-Oeste, Sudeste e Norte dos Cerrados (NASCIMENTO et al., 2014). A espécie é potencialmente útil, por apresentar importância socioeconômica, ecológica e medicinal. Possui relevante valor econômico para a região Nordeste, devido às diversas possibilidades de aproveitamento de seus frutos, como o consumo in natura, produção de sucos, doces, geleias, sorvetes e compotas (SOARES et al., 2011). É também utilizada na medicina

FLORESTA, Curitiba, PR, v. 46, n. 3, p. 335 - 342, jul. / set. 2016.

Oliveira, K. S. de et al.

ISSN eletrônico 1982-4688

DOI: $10.5380 /$ rf.v46i3.43993 
popular para o tratamento de lesões, inflamações, diarreia, tuberculose, úlceras, herpes e cólica menstrual (SILVA JUNIOR, 2004). Além das propriedades medicinais, possui potencial para a recuperação de áreas degradadas, permitindo sua utilização sustentável, podendo também servir de fonte de renda alternativa para populações locais que vivem desse recurso.

Em ambiente natural, a propagação é dificultada pelo fato de suas sementes serem recalcitrantes, caracterizadas pela rápida desidratação do embrião, além de a polpa do fruto exercer ação inibitória sobre a germinação das sementes (GRICOLETO, 1997). Além dos fatores que comprometem sua reprodução natural, a redução significativa dos campos nativos da mangabeira, bem como seu reflexo negativo na cadeia produtiva da mangaba, é resultado principalmente do desmatamento, da exploração econômica extrativista não sustentável, da intensa expansão imobiliária nas áreas de ocorrência natural e da prática de monocultura de cana-de-açúcar e coqueiro, o que tem contribuído cada vez mais para redução da diversidade genética da espécie, ameaçando-a de extinção (SÁ et al., 2011).

A esse propósito, as técnicas de biotecnologia vegetal com ênfase na cultura de tecidos surgem como uma alternativa para reduzir os impactos causados pelo uso não sustentável das espécies. Sendo assim, a propagação vegetativa in vitro (ou micropropagação) constitui uma excelente via de conservação para espécies como a mangabeira, pois contorna as condições que comprometem sua reprodução natural e promove a multiplicação em larga escala dos exemplares (ARAGÃO et al., 2011). Essa técnica pode ser empregada na formação de bancos de germoplasma para futuras pesquisas, estudos de reposição de mata nativa, implantação de cultivos comerciais e paisagismo (OLIVEIRA et al., 2014).

Nesse sentido, vale ressaltar que o sucesso da micropropagação depende de diversos fatores, entre eles a variação genotípica, o tipo e o tamanho do explante, o meio de cultura e as concentrações de reguladores de crescimento, sendo estes os principais responsáveis por estímulos de respostas para diferenciação, crescimento, multiplicação e alongamento celular (GRATTAPAGLIA; MACHADO, 1998). Diante disso, o balanço dos fitorreguladores mais utilizados em cultura de tecidos, auxina e citocinina, exercem diversos efeitos na diferenciação de parte aérea, raízes e formação de calos (REIS et al., 2004). As citocininas promovem a divisão celular e estão ligadas à diferenciação celular no processo de formação das partes aéreas e raízes, e as auxinas controlam o crescimento e alongamento celular, sobretudo na promoção de raízes laterais e adventícias (TAIZ; ZEIGER, 2009).

Entre os reguladores de crescimento, a citocinina 6-benzilaminopurina (BAP) é a mais utilizada, pois, dentro dessa classe, é o fitorregulador que tem se mostrado mais eficaz na multiplicação de diversas espécies lenhosas. Além disso, proporciona o menor custo de aquisição (ARAGÃO et al., 2011). Já em relação às auxinas, o ácido naftalenoacético (ANA) tem sido mais comumente utilizado, em concentrações que variam conforme a espécie e/ou cultivar, sendo utilizado com sucesso em combinação com outras citocininas, para estimular a indução e alongamento de brotos e o enraizamento em várias espécies vegetais (GRATTAPAGLIA; MACHADO, 1998).

Nesse contexto, o objetivo deste trabalho foi testar o efeito de diferentes concentrações de 6benzilaminopurina e ácido naftalenoacético sobre a indução de brotações em explantes nodais de mangabeira.

\section{MATERIAL E MÉTODOS}

O estudo foi conduzido no Laboratório de Biotecnologia de Conservação de Espécies Nativas (LABCEN) do Departamento de Botânica, Ecologia e Zoologia da Universidade Federal do Rio Grande do Norte (UFRN), em Natal, RN.

Segmentos nodais, provenientes de plantas germinadas in vitro com sementes originadas de frutos adquiridos em feiras populares no município de Natal, RN, foram utilizados como fonte de explante, sendo excisados com aproximadamente $1,0 \mathrm{~cm}$ de comprimento e em seguida inoculados verticalmente em frascos de vidro com capacidade de $150 \mathrm{~mL}$, contendo $20 \mathrm{~mL}$ de meio de cultura. O meio basal foi o MS básico (MURASHIGE; SKOOG, 1962), suplementado com 100 mg.L $\mathrm{L}^{-1}$ de inositol, 30 g.L ${ }^{-1}$ de sacarose, 7 g.L $\mathrm{L}^{-1}$ de ágar e diferentes concentrações de $\operatorname{BAP}\left(0,0 ; 1,5 ; 2,5\right.$ e $\left.3,5 \mathrm{mg} . \mathrm{L}^{-1}\right)$ e ANA $\left(0,0 ; 0,1\right.$ e $\left.0,5 \mathrm{mg} . \mathrm{L}^{-1}\right)$, permanecendo em sala de crescimento com fotoperíodo de 16 horas a uma intensidade luminosa de $60 \mu \mathrm{mol} \cdot \mathrm{m}^{-2} . \mathrm{s}^{-1}$, umidade relativa próxima a $76 \%$ e temperatura de $25 \pm 2{ }^{\circ} \mathrm{C}$.

$\mathrm{O}$ delineamento estatístico utilizado foi o inteiramente casualizado, composto por doze tratamentos e três repetições. Cada repetição continha 10 unidades experimentais (10 frascos). Cada unidade experimental era constituída por um único explante (nodal), inoculado em meio MS básico acrescido ou não de uma única dose dos fitorreguladores. Após 30 dias da inoculação, foram avaliados: explantes responsivos para a formação de brotos, o número de brotos/explante, formação de calos na base dos explantes, sobrevivência e contaminação.

Os dados obtidos foram submetidos a cinco análises de modelo linear generalizado (PAREDES et al., 2014), uma para cada variável resposta (V.R.), referentes aos explantes nodais (brotação, número médio de 
brotos, formação de calos, presença de contaminação e sobrevivência). Os dados de explantes nodais foram ajustados com as concentrações das variáveis explicativas (V.E.), BAP e ANA, utilizando-se o software R, versão 3.2.2 (2013). As V.R. com distribuição binomial (brotação, calos, contaminação e sobrevivência) foram ajustadas a partir da função de ligação Logit (modelo de regressão logística). No caso da V.R. brotos, por ser formado por variável quantitativa discreta (distribuição de Poisson), ajustou-se ao modelo log-linear (modelo de regressão de Poisson). Foi utilizado, nos modelos, o nível de significância ( $\alpha$ ) de $5 \%$.

\section{RESULTADOS E DISCUSSÃO}

Os modelos utilizados para a análise estatística da presença de brotações, formação de calos, presença de contaminação, sobrevivência e número de brotos por explante foram significativos $(p<0,05)$ para as diferentes concentrações de BAP e ANA, com exceção da variável contaminação, que foi significativa apenas para a utilização de BAP (Tabela 1).

Tabela 1. Estimativas dos parâmetros dos modelos ajustados para exprimir a relação entre as concentrações de BAP e ANA em $H$. speciosa.

Table 1. Estimates of models parameters adjusted to express the relation between BAP and NAA in H. speciosa.

\begin{tabular}{lccccc}
\hline Variável dependente & \multicolumn{2}{c}{ V.independente (Coeficientes) } & \multicolumn{2}{c}{ Valor de P* } \\
\hline Brotação & Intercepto & BAP & ANA & BAP & ANA \\
Formação de calos & 1,45 & $-0,34$ & $-1,46$ & 0,0001 & 0,004 \\
Contaminação & $-1,85$ & 0,46 & 2,64 & 0 & 0 \\
Sobrevivência & $-3,44$ & 0,7 & - & 0 & - \\
Número de brotos & 3,45 & $-0,64$ & 3,37 & 0,001 & 0,009 \\
\hline
\end{tabular}

* Foi utilizado nos testes o nível de significância de 0,05 .

Houve maior porcentagem de brotação na ausência de BAP e ANA (Figura 1A). No tratamento sem BAP, a porcentagem de brotação foi de $80 \%$, enquanto que, para ANA, foi de 55\%. Foi possível observar, ainda, um decréscimo na taxa de brotação conforme o aumento das concentrações desses reguladores de crescimento.
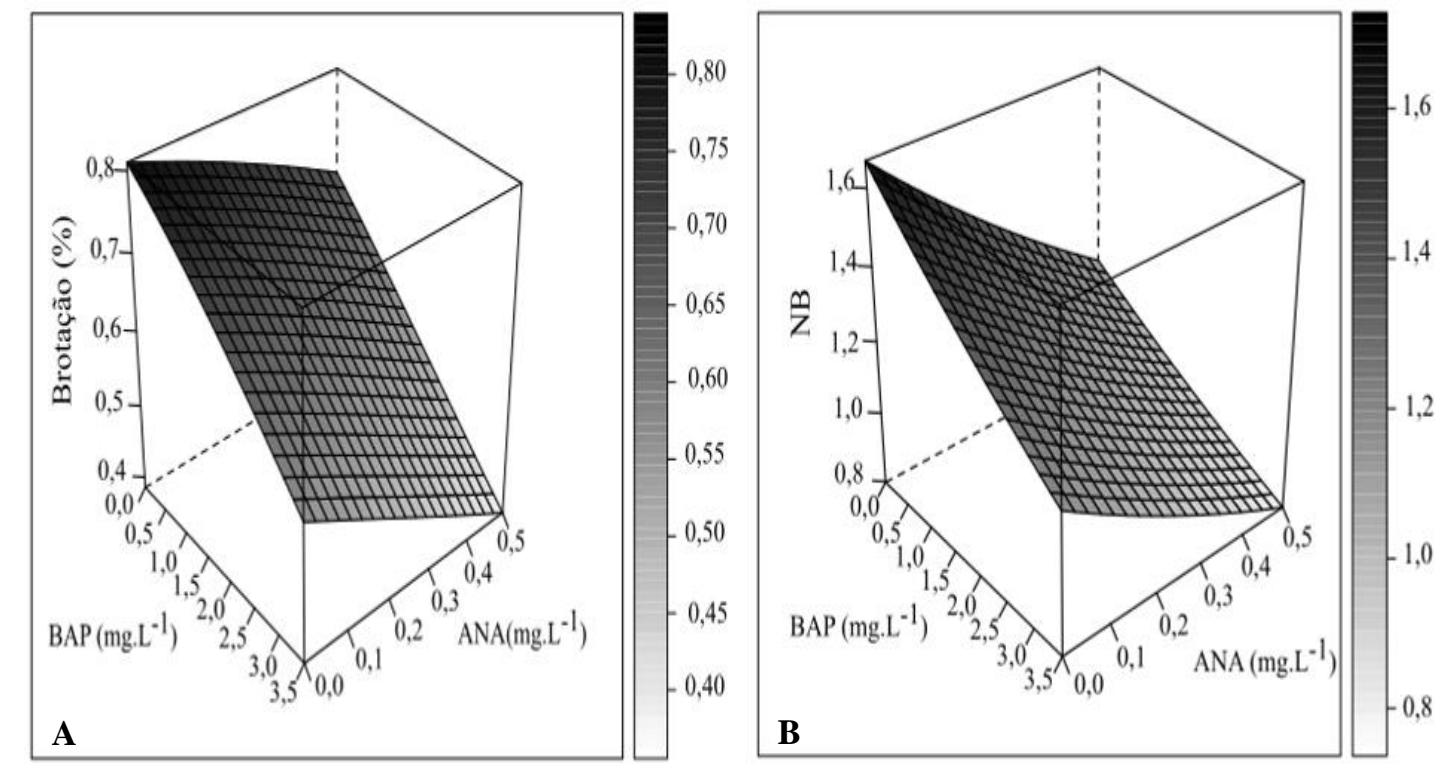

Figura 1. Porcentagem de brotação (A) e número médio de brotos por explantes (NB) (B), em explantes nodais de $H$. speciosa para cada concentração de BAP e ANA acrescentada ao meio de cultura MS básico, após 30 dias de cultivo.

Figure 1. Percentage of sprouting (A) and the average number of shoots per explants (NB) (B), nodal explants $H$. speciosa for each concentration of BAP and NAA added to the basic MS medium culture after 30 days of cultivation. 
A formação de brotações nos explantes caulinares de mangabeira foi observada em todos os tratamentos testados. No entanto, a utilização de reguladores de crescimento vegetal no meio nutritivo, nas concentrações testadas, não se mostrou eficiente para a indução de brotações em mangabeira, visto que o maior número de brotos foi obtido em meio de cultivo sem os fitorreguladores. O comportamento observado para a espécie sugere que não há necessidade de uma fonte exógena de citocinina para estimular a brotação em segmentos nodais de H. speciosa, provavelmente devido à existência de concentrações endógenas de citocinina suficientes para a indução de brotos (FERMINO JUNIOR; SCHERWINSKI-PEREIRA, 2012).

Os resultados diferem dos encontrados por Soares et al. (2007), em que os autores constataram que a utilização de BAP promoveu resposta eficiente na indução de multibrotações em segmentos nodais de mangabeira. Já Silva (2010), ao estudar o efeito do BAP e ANA em segmentos nodais da mesma espécie, observou que na ausência de BAP as brotações aumentaram. Os resultados corroboram os de Silva et al. (2014) em estudos com espécies lenhosas como a Caesalpinia pyramidalis, em que constataram aumento no número de brotações em meio de cultura sem reguladores vegetais, o que evidencia que concentrações mais elevadas dessa citocinina foram inibitórias para o processo de multiplicação.

Os tratamentos com as concentrações de 1,5 ou 2,5 mg. $\mathrm{L}^{-1}$ de BAP associados com $0,5 \mathrm{mg} . \mathrm{L}^{-1}$ de ANA proporcionaram baixo índice de multiplicação dos explantes. Além disso, essas brotações não se desenvolveram satisfatoriamente. Tal comportamento observado pode ser atribuído ao fato de o balanço hormonal entre as concentrações de auxina e citocinina utilizadas ter favorecido a calogênese, interferindo diretamente no desenvolvimento de brotos e da parte aérea. Os resultados diferem dos obtidos por Araújo et al. (2008), que, ao estudarem o efeito conjugado de ANA e BAP em explantes de abacaxizeiro 'smooth cayenne', verificaram que a associação de 0,5 ou 1,0 mg. $\mathrm{L}^{-1}$ de ANA e 1,0 ou 2,0 mg.L ${ }^{-1}$ de BAP promoveu boa multiplicação dos explantes. No entanto os autores explicam que houve pouco desenvolvimento das brotações, além de se mostrarem difíceis de serem subcultivadas. De acordo com Cheng et al. (2013), a interação entre baixas concentrações de auxinas e concentrações mais elevadas de citocininas pode favorecer a indução de brotações, por estimular mais ainda as divisões celulares. Entretanto a presença de auxina em concentrações elevadas pode estimular a indução de calos.

Por outro lado, quando se estudou o efeito isolado das concentrações de 0,1 e $0,5 \mathrm{mg} . \mathrm{L}^{-1}$ de ANA, ambas as concentrações reduziram a multiplicação de brotos, embora tenham favorecido o desenvolvimento da parte aérea (Figura 1A). No entanto, quando a auxina foi combinada com diferentes concentrações de BAP, concentrações acima de $0,1 \mathrm{mg} . \mathrm{L}^{-1}$ de ANA promoveram redução significativa na formação de brotos. Nesse sentido, Hu e Wang (1983) destacam que as auxinas, como ANA, podem estimular respostas variadas in vitro, e que a citocinina BAP induz a formação de grande número de brotos e alta taxa de multiplicação em sistemas de micropropagação, o que pode explicar as diferenças de resultados. Nesta pesquisa, o aumento na concentração de BAP promoveu comportamento diferente, reduzindo significativamente as taxas de multiplicação in vitro.

Para número de brotos por explantes, observou-se uma redução nas médias à medida que houve aumento na concentração das citocininas e auxinas no meio de cultura (Figura 1B). No tratamento sem BAP, o número médio de brotos foi de 1,7, enquanto que, para ANA, foi de 1,2. Os resultados diferem dos encontrados por Reis (2011), que em estudos com a mesma espécie não verificou diferença significativa ao analisar as concentrações de 0 a 4 mg. $\mathrm{L}^{-1}$ de BAP combinada com 0 a 1,5 mg. $\mathrm{L}^{-1}$ de ANA. Os autores constataram o menor número de brotações na ausência de BAP (1,2 brotos) e na máxima concentração utilizada (1,46 brotos).

Os resultados em número de brotações citados acima diferem dos encontrados por Soares (2008), que, em estudos com a mesma espécie, constatou que a adição de ANA até a concentração de $0,1 \mathrm{mg} . \mathrm{L}^{-1}$ combinada com 2,0 mg. $\mathrm{L}^{-1}$ de BAP favoreceu o incremento do número de brotos formados (4,3 por explante). De acordo com a autora, concentrações acima dessa dose promovem redução nos valores dessa variável. Por outro lado, para a espécie Passiflora foetida, em estudo realizado por Anand et al. (2012), o melhor alongamento de brotos foi obtido utilizando segmentos nodais em meio MS suplementado com 1,5 mg. $\mathrm{L}^{-1}$ de BAP + 0,5 mg.L $\mathrm{L}^{-1} \mathrm{de}$ ANA.

Também foi observado um decréscimo na porcentagem de sobrevivência conforme o aumento das concentrações de citocinina, enquanto que a adição de auxina favoreceu a sobrevivência dos explantes nodais de mangabeira (Figura 2A). No tratamento sem BAP, a taxa de sobrevivência foi $100 \%$, enquanto que, para $0,5 \mathrm{mg} . \mathrm{L}^{-1}$ de ANA, foi de $95 \%$. Os resultados diferem dos obtidos por Morais et al. (2014) que, ao estudarem as concentrações de 0 a 4,0 mg. $\mathrm{L}^{-1}$ de BAP no cultivo in vitro de hortelã-pimenta (Mentha x Piperita L.), constataram o aumento na porcentagem de sobrevivência dos explantes ao elevarem a dose desse fitorregulador. Possivelmente, para essa espécie, a adição de BAP nas concentrações utilizadas favoreceu a sobrevivência em razão de essa citocinina participar do retardamento da senescência de tecidos e órgão vegetais, consequentemente, aumentando a longevidade celular (MORGANTE; LOMBARDI, 2004).

Houve maior porcentagem de formação de calos com o acréscimo nas concentrações de BAP e ANA, sendo que o tratamento com 3,5 mg. $\mathrm{L}^{-1}$ de BAP apresentou $40 \%$, enquanto que, para $0,5 \mathrm{mg} . \mathrm{L}^{-1}$ de ANA, foi de $75 \%$ (Figura 2B). Foi possível observar, ainda, um aumento na taxa de formação de calos conforme o aumento das concentrações desses reguladores de crescimento. Resultados semelhantes também foram observados com a 
mesma espécie e em culturas de outras espécies lenhosas, como Caesalpinia echinata e C. pyramidalis (SOARES et al., 2007; ARAGÃO et al., 2011; SILVA, 2014).

A elevada formação de calos no tratamento com $0,5 \mathrm{mg} \cdot \mathrm{L}^{-1}$ de ANA em combinação com 1,5 e $2,5 \mathrm{mg} . \mathrm{L}^{-1}$ de BAP pode, portanto, explicar o reduzido número de brotações alongadas, bem como seu desenvolvimento (Figura 3). A calogênese na base dos explantes pode inviabilizar a multiplicação de gemas axilares e o alongamento de brotações, comprometendo o desenvolvimento in vitro (GRATTAPAGLIA; MACHADO, 1998). Nesse sentido, pode-se inferir que as respostas obtidas no presente estudo corroboram as de Navroski et al. (2013), ao afirmarem que a formação dessas estruturas interfere diretamente no cultivo in vitro, quando se objetiva a propagação direta.
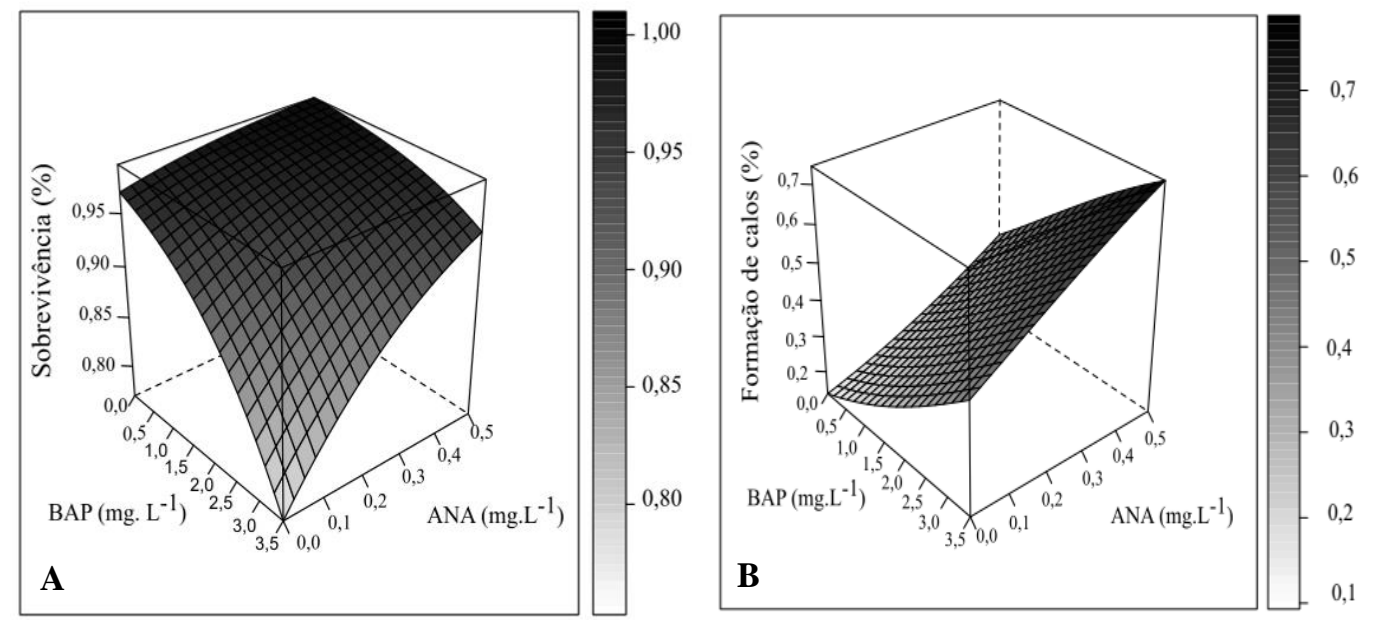

Figura 2. Porcentagem de sobrevivência (A) e formação de calos (B) em explantes nodais de H. speciosa para cada concentração de BAP e ANA acrescentada ao meio de cultura MS básico, após 30 dias de cultivo.

Figure 2. Survival percentage (A) and callus formation (B), nodal explants $H$. speciosa for each concentration of BAP and NAA added to the basic MS medium culture after 30 days of cultivation.

Observou-se, ainda, que a interação de $0,5 \mathrm{mg} . \mathrm{L}^{-1}$ de ANA + 1,5 mg. $\mathrm{L}^{-1}$ de BAP favoreceu a formação de calos friáveis na base dos segmentos nodais, geralmente maiores em relação às concentrações de 2,5 e 3,5 mg. $\mathrm{L}^{-1}$ de BAP. Nesses tratamentos, houve pouco desenvolvimento de brotações e maior crescimento de calos (Figura 3). No entanto, constatou-se o aumento na oxidação dos calos, principalmente nas concentrações de 1,5 e 2,5 mg. $L^{-1}$ de BAP. Neste estudo, foi possível observar também, de forma geral, diferença na pigmentação e tamanho dos calos formados, que variaram de acordo com a concentração de BAP e ANA. Na concentração de $2,5 \mathrm{mg} . \mathrm{L}^{-1}$ de BAP + 0,5 mg. $\mathrm{L}^{-1}$ de ANA, os calos apresentaram uma coloração vermelhoesverdeada. Já na concentração de $1,5 \mathrm{mg} . \mathrm{L}^{-1}$ de BAP + 0,1 mg. $\mathrm{L}^{-1}$ de ANA, coloração amarelo-esverdeada.
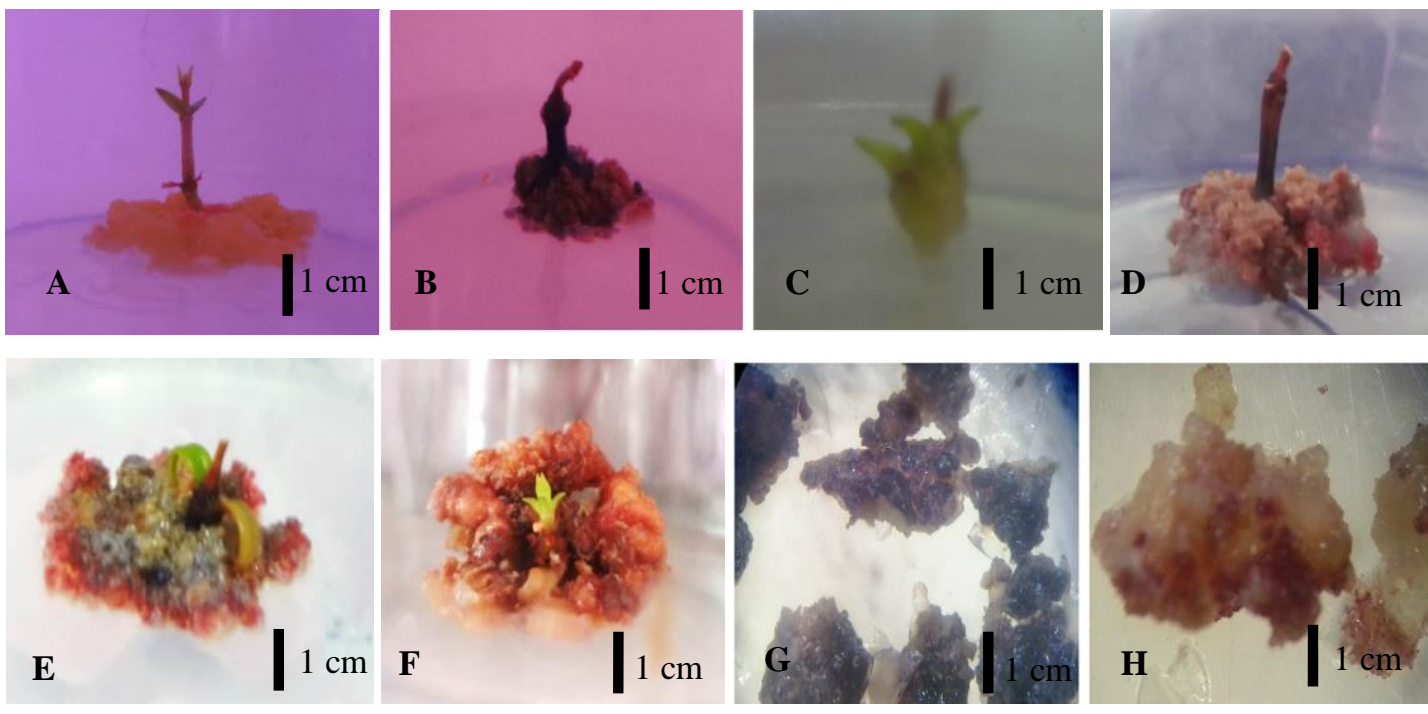

FLORESTA, Curitiba, PR, v. 46, n. 3, p. 335 - 342, jul. / set. 2016.

Oliveira, K. S. de et al.

ISSN eletrônico 1982-4688

DOI: $10.5380 /$ rf.v46i3.43993 

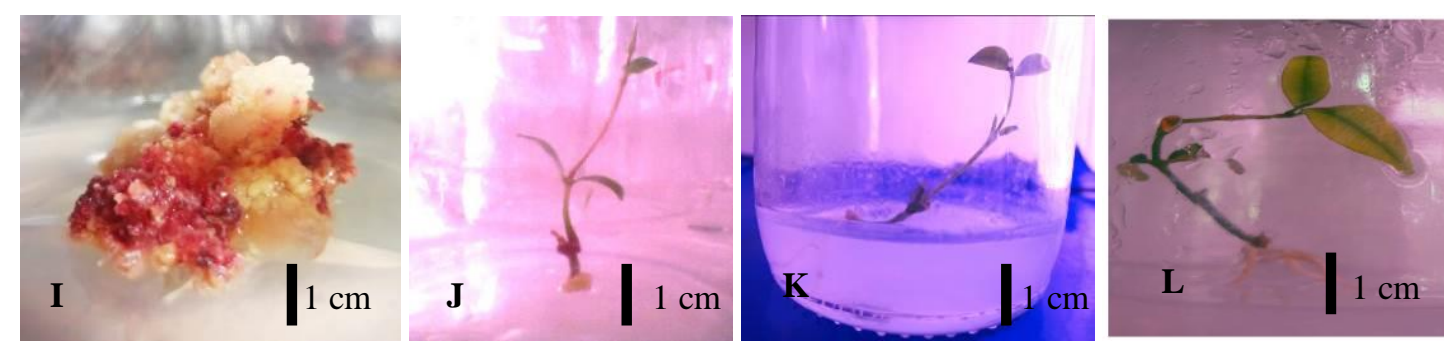

Figura 3. Aspecto visual da formação de calos em explantes nodais de H. speciosa sob o efeito conjugado de diferentes concentrações de BAP e ANA. A) $1,5 \mathrm{mg} . \mathrm{L}^{-1}$ de BAP + 0,1 mg. $\mathrm{L}^{-1}$ de ANA; B) $2,5 \mathrm{mg} . \mathrm{L}^{-1}$

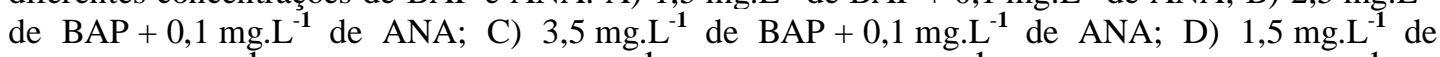

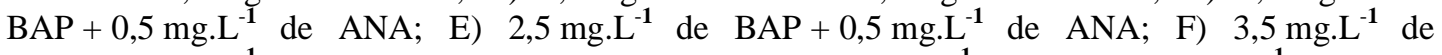

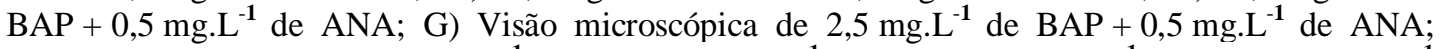
H) Visão microscópica de 3,5 mg.L $\mathrm{L}^{-1}$ de BAP + 0,5 mg.. $\mathrm{L}^{-1}$ de ANA; I) 3,5 mg. $\mathrm{L}^{-1}$ de BAP + 0,1 mg.L $\mathrm{L}^{-1}$ de ANA; J) e K) Efeito isolado de BAP; L) Efeito isolado de ANA.

Figure 3. Visual appearance of callus formation in nodal explants $H$. speciosa under the combined effect of different concentrations of BAP and ANA. A) $1.5 \mathrm{mg} \cdot \mathrm{L}^{-1}$ of BAP $+0.1 \mathrm{mg} \cdot \mathrm{L}^{-1} \mathrm{NAA}$; B) $2.5 \mathrm{mg} \cdot \mathrm{L}^{-1}$ of BAP + $0.1 \mathrm{mg} . \mathrm{L}^{-1} \mathrm{NAA}$; C) $3.5 \mathrm{mg} . \mathrm{L}^{-1} \mathrm{BAP}+0.1 \mathrm{mg} . \mathrm{L}^{-1} \mathrm{NAA}$; D) $1.5 \mathrm{mg} . \mathrm{L}^{-1} \mathrm{BAP}+0.5 \mathrm{mg} \cdot \mathrm{L}^{-1} \mathrm{NAA}$; E) $2.5 \mathrm{mg} \cdot \mathrm{L}^{-1} \mathrm{BAP}+0.5 \mathrm{mg} \cdot \mathrm{L}^{-1} \mathrm{NAA}$; F) $3.5 \mathrm{mg} \cdot \mathrm{L}^{-1} \mathrm{BAP}+0.5 \mathrm{mg} \cdot \mathrm{L}^{-1} \mathrm{NAA}$; G) Microscopic view of $2.5 \mathrm{mg} . \mathrm{L}^{-1}$ of $\left.\mathrm{BAP}+0.5 \mathrm{mg} . \mathrm{L}^{-1} \mathrm{NAA} ; \mathrm{H}\right)$ Microscopic view of $3.5 \mathrm{mg} . \mathrm{L}^{-1}$ of $\mathrm{BAP}+0.5 \mathrm{mg} . \mathrm{L}^{-1}$ NAA. I) $3.5 \mathrm{mg} . \mathrm{L}^{-1} \mathrm{BAP}+0.1 \mathrm{mg} . \mathrm{L}^{-1} \mathrm{NAA}$; J) and K) Isolated BAP effect; L) Effect isolated ANA.

Houve maior porcentagem de contaminação na presença de BAP. No tratamento com $3,5 \mathrm{mg} \cdot \mathrm{L}^{-1}$ de BAP, a taxa de contaminação foi de $30 \%$, enquanto, para ANA, não foi observada influência significativa, independentemente da concentração utilizada (Figura 4). Foi possível observar, ainda, um aumento na porcentagem de contaminação conforme o aumento da concentração da citocinina. Os resultados corroboram os de Bezerra et al. (2014), que também verificaram uma tendência a maiores índices de contaminação com o aumento na concentração de BAP em explantes de M. caesalpiniifolia. Nesse sentido, pode-se inferir que, possivelmente, concentrações elevadas da citocinina tenham apresentado efeito tóxico, comprometendo a multiplicação e o desenvolvimento do explante e, consequentemente, contribuído para sua degradação. Tais condições podem ter favorecido a proliferação de microrganismos endógenos, que passaram a competir por nutrientes minerais e carboidratos do meio de cultura (BATAGIN-PIOTTO, 2013), provocando com isso a necrose pela colonização de seus tecidos. Outro fator que pode ter contribuído para a presença desses contaminantes endógenos pode estar relacionado à exsudação de látex característico da mangabeira e que provavelmente seja uma importante fonte de microrganismos.

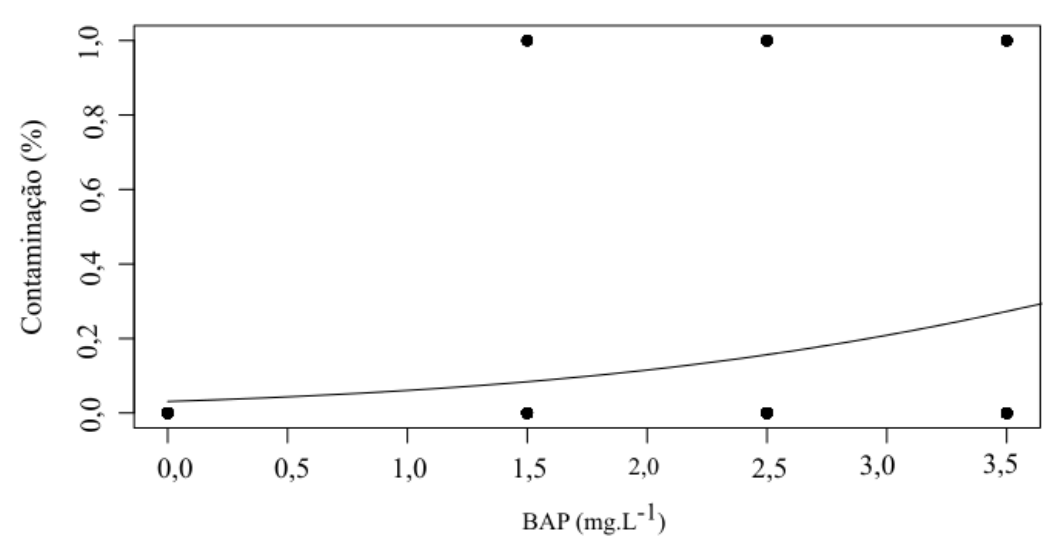

Figura 4. Porcentagem de contaminação em explantes nodais de $H$. speciosa para cada concentração de BAP acrescentada ao meio de cultura MS básico, após 30 dias de cultivo.

Figure 4. Percentage of contamination in nodal explants $H$. speciosa for each concentration of BAP added to the means of basic MS culture after 30 days of culture.

A partir dos resultados, compreende-se que a espécie $H$. speciosa comporta-se de maneira diferente quanto à multiplicação in vitro quando submetida à ação de diferentes concentrações de BAP e ANA testadas em

FLORESTA, Curitiba, PR, v. 46, n. 3, p. 335 - 342, jul. / set. 2016.

Oliveira, K. S. de et al. 
explantes nodais, e que a adição de ácido naftalenoacético ao meio de cultivo suplementado com 6benzilaminupurina não favorece a indução de brotos da espécie. No entanto, sugere-se a realização de novas pesquisas utilizando diferentes concentrações desses reguladores, combinadas com diferentes tempos de exposição à auxina ou outras fontes de fitorreguladores, para aumentar as taxas de multiplicação e o enraizamento in vitro, de forma a viabilizar a aclimatização das plantas.

\section{CONCLUSÕES}

- A ausência de BAP e ANA aumenta significativamente a taxa de multiplicação, bem como o número de brotações de $H$. speciosa.

- Concentrações superiores desses reguladores de crescimento vegetal promovem a formação de calos.

- A adição de ANA ao meio de cultura favorece a taxa de sobrevivência, enquanto o BAP apresenta efeito antagônico.

- A multiplicação in vitro em segmentos nodais de mangabeira é mais responsiva na ausência de reguladores de crescimento vegetal.

\section{AGRADECIMENTOS}

À Coordenação de Aperfeiçoamento de Pessoal de Nível Superior (CAPES), pela concessão de bolsa de pesquisa à primeira autora.

\section{REFERÊNCIAS}

ANAND, S. P.; JAYAKUMAR, E.; JEYACHANDRAN, R.; NANDAGOBALAN, V.; DOSS, A. Direct Organogenesis of Passiflora foetida L. through nodal explants. Plant Tissue Culture and Biotechnology, v. 22, n. 1, p. 87-91, 2012.

ARAGÃO, A. K. O; ALOUFA, M. A. I.; COSTA, I. do A. Efeito do BAP (6-benzilaminopurina) sobre a indução de brotos em explantes de pau-brasil. Cerne, v. 17, p. 339-345, 2011.

ARAÚJO, R. F.; SIQUEIRA, D. L.; CECON, P. R. Multiplicação in vitro do abacaxizeiro 'smooth cayenne' utilizando benzilaminopurina (BAP) e ácido naftalenoacético (ANA). Revista Ceres, v. 55, n. 5, p. 455-460, 2008.

BATAGIN-PIOTTO, K. D. Avaliação da atuação da manifestação bacteriana no desenvolvimento in vitro de clones de Eucalyptus benthamii Maiden \& Cambage. 2013. 157 p. Tese (Doutorado em Fisiologia e Bioquímica de Plantas) - Escola Superior de Agricultura "Luiz de Queiroz", Universidade de São Paulo, Piracicaba, 2013.

BEZERRA, R. M. de F.; AlOUFA, M. A. I.; FREIRE, F. A. de M.; SANTOS, D. D. dos. Efeito de 6benzilaminopurina sobre a propagação in vitro de Mimosa caesalpiniifolia Benth. (Fabaceae). Revista Árvore, Viçosa-MG, v. 38, n. 5, p. 771-778, 2014.

CHENG, Z. J.; WANG, L.; SUN, W.; ZHANG, Y.; ZHOU, C.; SU, Y. H.; LI, W.; SUN, T. T.; ZHAO, X. Y.; LI, X. G.; CHENG, Y.; ZHAO, Y.; XIE, Q.; ZHANG, X. S. Patern of auxin and cytokinin responses for shoot meristema induction results from the regulation of cytokinin biosynthesis by AUXIN RESPNSES FACTOR 3. Plant Physiology, Bethesda, v. 161, n. 1, p. 240-251, 2013.

FERMINO JUNIOR, P. C. P.; SCHERWINSKI-PEREIRA, J. E. Germinação e propagação in vitro de cerejeira (Amburana acreana (Ducke) A. C. Smith - Fabaceae). Ciência Florestal, Santa Maria, v. 22, n. 1, p. 1-9, 2012.

GRATTAPAGLIA, D.; MACHADO, M. A. Micropropagação. In. TORRES, A. C.; CALDAS, L. S.; BUSO, J. A. (Org.). Cultura de tecidos e transformação de genética de plantas. 1. ed. Brasília: SPI, v. 1, 1998. p. 183260.

GRICOLETTO, E. R. Micropropagação de Hancornia speciosa Gomes (Mangabeira). 76 f. Dissertação (Mestrado em Biologia Vegetal) - Universidade Estadual de Brasília, Brasília, DF, 1997.

HU, C. Y.; WANG, P. J. (1983). Meristem, shoot tip, and bud cultores. In: EVANS, D. A.; SHARP, W. R.; AMMIRATO, P. V.; YAMADA, Y. (Eds.). Handbook of plant cell culture. New York. p. 177-227.

MORAIS, T. P.; ASMAR, S. A.; LUZ, J. M. Q. Reguladores de crescimento vegetal no cultivo in vitro de Mentha x Piperita L. Revista Brasileira de Plantas Medicinais, Campinas, v. 16, n. 2, supl. I, p. 350-355, 2014.

FLORESTA, Curitiba, PR, v. 46, n. 3, p. 335 - 342, jul. / set. 2016.

Oliveira, K. S. de et al.

ISSN eletrônico 1982-4688

DOI: $10.5380 /$ rf.v46i3.43993 
MORGANTE, C. V.; LOMBARDI, S. P. Hormônios vegetais e biotecnologia. Piracicaba: Esalq, 2004.13 p.

MURASHIGE, T.; SKOOG, F. A revised medium for rapid growth and bioassays with tobacco tissue cultures. Physiologia Plantarum, v. 15, p. 473-497, 1962.

NASCIMENTO, R. S. M.; CARDOSO, J. A.; COCOZZA, F. D. M. Caracterização física e físico-química de frutos de mangabeira (Hancornia speciosa Gomes) no oeste da Bahia. Revista Brasileira de Engenharia Agrícola e Ambiental, v. 18, n. 8, p. 856-860, 2014.

NAVROSKI, M. C.; REINIGER, L. R. S.; PEREIRA, M. de O.; CURTI, A. R.; PAIM, A. F. Alongamento in vitro de genótipos de Eucalyptus dunnii Maiden. Revista Cerne, v. 19, n. 4, Lavras, 2013.

OLIVEIRA, K. S. de; OLIVEIRA, M. da S.; PEREIRA, E. C.; LIMA, S. C. de; ALOUFA, M. A. I. Efeito de diferentes meios de cultura na germinação in vitro de sementes de mangabeira (Hancornia speciosa Gomes). Revista Árvore, Viçosa-MG, v. 38, n. 4, p. 601-607, 2014.

PAREDES, K.; DELAVEAU, C.; CARRASCO, P.; BAEZA, C.; MORA, F.; URIBE, M. E. In vitro bulbing for the propagation of Traubia modesta (Amaryllidaceae), a threatened plant endemic to Chile. Cien. Inv. Agr., v. 41, n. 2, p. 207-214, 2014.

R Development Core Team. R: A language and environment for statistical computing. R Foundation for Statistical Computing, Vienna, Austria. 2013. Disponível em: 〈http://www.R-project.org/>.

REIS, C. V. dos; SOUSA, C. M.; CARVALHO, A. C. P. P. de; MIRANDA, R. M. Efeitos do tipo de explante e diferentes balanços de auxina e citocinina na regeneração in vitro de Catharanthus roseus (L.) G. DON. Agronomia, v. 38, n.1, p. 93-97, 2004.

REIS, L. L. dos. Propagação de Hancornia speciosa Gomes - Apocynaceae, por alporquia e micropropagação. 105 f. Dissertação (Mestrado em Agronomia) - Universidade Estadual Paulista, Ilha Solteira, 2011.

SÁ, A. de J.; LÉDO, A. da S.; LÉDO, C. A. da S. Conservação in vitro de mangabeira da região Nordeste do Brasil. Ciência Rural, v. 41, n. 1, p. 57-62, 2011.

SILVA, E. de O. Propagação e armazenamento de sementes de mangabeira (Hancornia speciosa Gomes). 105 f. Dissertação (Mestrado em Agronomia) - Centro de Ciências Agrárias, Universidade Federal da Paraíba, Areia, 2010

SILVA JUNIOR, J. F. da. A cultura da mangaba. Revista Brasileira de Fruticultura, Jaboticabal, v. 26, n. 1, p. 1-192, 2004.

SILVA, T. dos S.; NEPOMUCENO, C. F.; BORGES, B. P. dos S.; ALVIM, B. F. M.; SANTANA, J. R. F. de S. Multiplicação in vitro de Caesalpinia pyramidalis (Leguminosae). Sitientibus série Ciências Biológicas, v. 13, p. 1-6, 2014.

SOARES, F. P.; PAIVA, R.; ALVARENGA A. A.; NOGUEIRA, R. C.; EMRICH, E. B.; MARTINOTTO, C. Organogênese direta em explantes caulinares de mangabeira (Hancornia speciosa Gomes). Ciência e Agrotecnologia, Lavras, v. 31, n. 4, p. 1048-1053, 2007.

SOARES, F. P. Influência das citocininas nos aspectos anatômicos, bioquímicos e fisiológicos do cultivo in vitro da mangabeira (Hancornia speciosa Gomes). 75 f. Tese (Doutorado em Agronomia/Fisiologia Vegetal) Universidade Federal de Lavras, Lavras, MG, 2008.

SOARES, F. P.; PAIVA, R.; ALVARENGA, A. A. de; NERY, F. C.; VARGAS, D. P.; SILVA, D. R. G. Taxa de multiplicação e efeito residual de diferentes fontes de citocinina no cultivo in vitro de Hancornia speciosa Gomes. Ciênc. Agrotec., Lavras, v. 35, n. 1, p. 152-157, 2011.

TAIZ, L.; ZEIGER, E. Fisiologia Vegetal. 4. ed. Trad. de E. R. Santarém. Porto Alegre: Artmed, 2009.720 p. 